Case Report

\title{
Malignant melanoma arising within ovarian mature cystic teratoma
}

\author{
Aasiya Rajbhandari ${ }^{1}$, Usha Manandhar ${ }^{1}$ \\ ${ }^{1}$ Department of Pathology, Tribhuvan University Teaching Hospital, Kathmandu, Nepal.
}

\section{Keywords: \\ Dermoid Cyst; \\ Malignant Melanoma; \\ Mature Cystic Teratoma; \\ Ovarian Melanoma;}

\begin{abstract}
Mature cystic teratomas are frequently encountered neoplasms of the ovary that comprise of tissues derived from all three germ layers. They are benign neoplasms with malignant transformation noted rarely in around 0.17 to $2 \%$ cases. Among the various transformations, malignant melanoma is one of the least commonly encountered. Here, we report a case of 41 years old female with malignant melanoma arising within mature cystic teratoma.
\end{abstract}

\section{Correspondence:}

Dr. Aasiya Rajbhandari

Resident, Department of Pathology

Tribhuvan University Teaching Hospital, Kathmandu, Nepal.

ORCID ID: 0000-0002-2854-8241

Email:aasyarb@gmail.com

Received : January $9^{\text {th }} 2019$; Accepted : March 14 $4^{\text {th }} 2019$; Published : March $29^{\text {th }} 2019$

Citation: Rajbhandari A, Manandhar U. Malignant melanoma arising within ovarian mature cystic teratoma. J Pathol Nep 2019;9:1508-10. DOI: 10.3126/jpn.v9i1.23383

Copyright: This is an open-access article distributed under the terms of the Creative Commons Attribution 4.0 International License, which permits unrestricted use, distribution, and reproduction in any medium, provided the original author and source are credited.

\section{INTRODUCTION}

Mature cystic teratomas (MCTs) are benign ovarian neoplasms comprising approximately $20 \%$ of all ovarian neoplasms. ${ }^{1}$ Also known as dermoid cyst, these tumors are composed of well differentiated structures derived from the three germ layers: ectoderm, mesoderm and endoderm. The ectodermal elements are usually are more frequent findings in these cysts.

Malignant transformation is an uncommon complication of MCTs noted in around 0.17 to $2 \%$ of the cases. ${ }^{2}$ It is noted in postmenopausal women with rare occurrence in young women. ${ }^{3}$ Any component of the teratoma can undergo malignant transformation, squamous cell carcinoma being the commonest. Other malignancies can be adenocarcinomas, cutaneous adnexal carcinomas, thyroid carcinomas, sarcomas and carcinoids. Sometimes, multiple types of malignancies can also be seen within a single teratoma. Malignant melanoma is rarely encountered with $0.2-0.8 \%$ incidence. $^{4}$ 


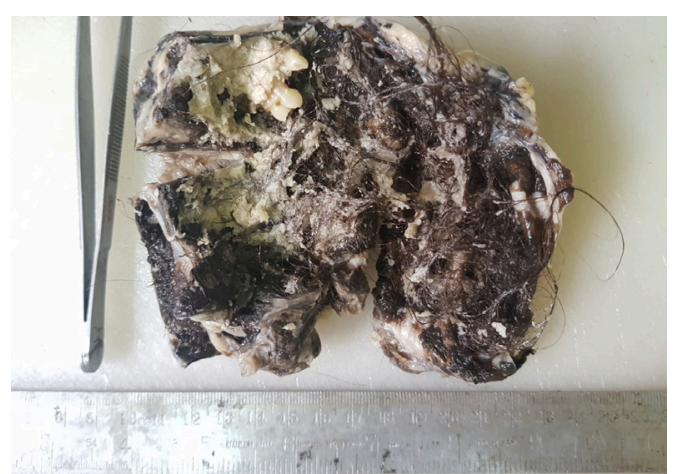

Figure 1: Gross photograph of ovary showing solid dark black walls and cystic areas filled with cheesy material, hair follicles and few teeth. .

\section{CASE REPORT}

A 41 years old, para 1 female presented to gynecology OPD with complaints of pain abdomen for five months and abdominal mass noticed since two weeks. On per vaginal examination, a suprapubic solid cystic mass was felt pushing the uterus towards the left side. Computed tomography (CT) revealed right abdomino-pelvic cystic lesion with solid areas and areas of calcifications, suggestive of dermoid cyst. Tumor markers were not done since there was no preoperative suspicion of malignant transformation within the MCT. She underwent total abdominal hysterectomy and bilateral salpingo-oophorectomy.

Gross examination of the received specimen showed a multiloculated right ovarian mass measuring $12 \times 11 \times 10 \mathrm{~cm}$ with intact capsule and solid and cystic areas on cutsection. The solid areas and cyst wall appeared black in color with cheesy material, hair follicles and few teeth filling the cystic cavity (fig.1). Microscopic examination showed components of MCT in the form of keratinized stratified squamous epithelium lining the cyst with wall composed of adnexal structures, glial tissue, bone, muscle and adipocytes. The solid areas showed diffuse proliferation of pleomorphic oval to spindle shaped cells large oval nuclei, prominent eosinophilic nucleoli and moderate amount of cytoplasm with melanin pigment deposition in most of the cells (fig. 2). Areas with necrosis were also present. Mitosis constituted 9/10 HPF with few atypical mitotic figures. On immunohistochemistry, the tumor cells were strongly positive for HMB-45 and S-100 (fig. 3). Thus, a diagnosis of malignant melanoma arising within a MCT was made.

\section{DISCUSSION}

MCTs of the ovary are usually benign tumors composed of cell types derived from one or more of the three germ cell layers (ectoderm, mesoderm and endoderm). Ectodermal components like the skin and its adnexa, mesodermal components like fat and muscle and endodermal components

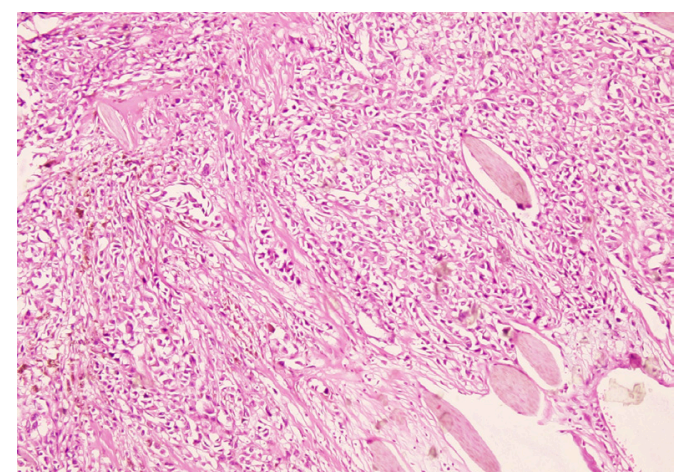

Figure 2: Low power view showing multiple hair shafts surrounded by tumor cells arranged in sheets with scattered cells showing melanin pigment deposition. (HE stain, X100)

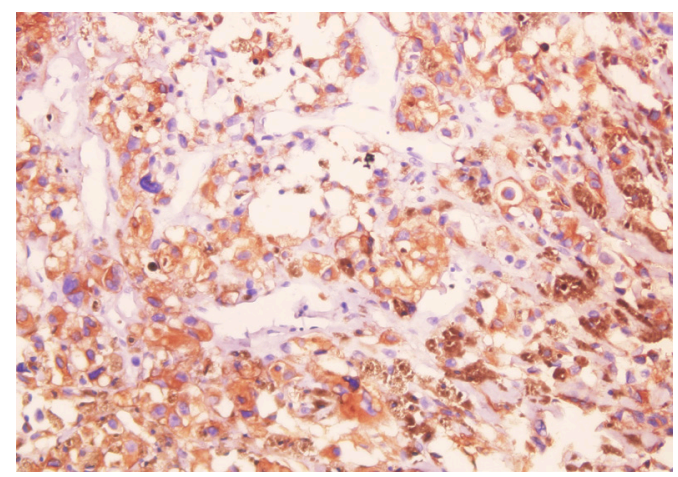

Figure 3: Tumor cells showing immunoreactivity for HMB45. Some cells on the right show denser granular melanin deposits. (HMB45 stain, X400)

like gastrointestinal and glial tissue are commonly seen. MCT arises from germ cells by failure of second meiotic division. MCT is most common in adolescents and women of reproductive age group. They usually show no signs or symptoms with incidental detection during examinations; sometimes abdominal pain, mass or abnormal uterine bleeding maybe the presenting symptom. Possible complications include torsion, malignant transformation, rupture and infection.

Malignant transformation is an uncommon complication. The risk of malignancy is related to advancing age and is substantially greater in postmenopausal women, the highest incidence being in the fifth and sixth decades of life. ${ }^{5}$ However, cases have been reported in menstruating females ${ }^{6}$ similar to our case who was having normal menstrual cycles. These tumors are more solid and tend to occur in patients with unilateral tumor with larger sizes than benign teratomas. ${ }^{7}$ Malignancies that have been reported include squamous cell carcinoma, basal cell carcinoma, malignant melanoma, sebaceous carcinoma, adenocarcinomas, sarcomas, carcinoid and neuroectodermal tumors. ${ }^{7}$ Of these, $85 \%$ of the cases are squamous cell carcinomas and adenocarcinoma accounts for $7 \%$ cases. 
Primary ovarian melanoma is a rare entity, as most ovarian melanoma is metastatic lesion from other sites. Primary ovarian melanoma arises as a component of MCT and melanoma arising from ovarian parenchyma in the absence of MCT has not been reported. Melanoma may arise from melanocytic component of a MCT such as dermo-epidermal (DE) junction, meningeal or uveal epithelium or benign pigmented lesions. In some cases, the tumor may destroy the D-E junction from which it arose. DE junctional activity was found in $50 \%$ of the cases only in a study by Ueda et al. ${ }^{8}$ Such DE junctional activity was not noted in our case.

Our case was labelled as primary ovarian melanoma of ovary as it meets the criteria laid by Broughton et al. that is the tumor being unilateral with teratoid elements and no demonstrable extraovarian primary melanoma. ${ }^{9}$

Previous literatures report aggressive behavior of primary ovarian malignant melanomas with $50 \%$ survival at the end of two years and worse prognosis than squamous cell carcinoma arising in a $\mathrm{MCT}^{6}$

\section{CONCLUSION}

Malignant transformation of MCTs is a rare occurrence and among such transformations, malignant melanoma arising within a MCT is very infrequent. When encountering such lesions, extra-ovarian primary melanoma and other teratoid elements within the tumor should be sought for to label a case as malignant melanoma arising in a MCT.

\section{Conflict of Interest: None}

\section{REFERENCES}

1. Talerman A, Vang R. Germ cell tumors of the ovary. In: Kurman RJ, Ellenson LH, Ronnett BM, editors. Blaustein's Pathology of the Female Genital Tract. New York :Springer, 2011. p 848-908 Crossref
2. Mandal S, Badhe BA. Malignant transformation in a mature teratoma with metastatic deposits in the omentum: a case report. Case Rep Pathol.2012;2012:568062. Crossref

3. Souaf I, Fatemi H El, Bennani A, Leila C, Nawale H. Papillary Carcinoma Derived from Ovarian Mature Cystic Teratoma: A New Case Report and Literature Review. Case Reports in Clinical Medicine 2014;3:197-202. $\underline{\text { Crossref }}$

4. Kudva R, Ayachit GS, Ayachit A. Malignant melanoma arising in an ovarian mature cystic teratoma - a rare entity. J Clin Diagn Res [Internet]. 2015;9(4):ED14-6. Crossref

5. Tanhiser J, Mahdi H, Rosa G, et al. Prostate-Type Adenocarcinoma in Mature Cystic Ovarian Teratoma. Int J Gynecol Pathol [Internet]. 2016;35:185-90. Crossref

6. Suneja A, Yadav P, Sharma A, Vaid NB, Singh B, Grover RK. Primary malignant melanoma in cystic teratoma of ovary. Indian $\mathrm{J}$ Cancer [Internet]. 2009;46:340-2. $\underline{\text { Crossref }}$

7. Park C-H, Jung M-H, Ji Y-I. Risk factors for malignant transformation of mature cystic teratoma. Obstet Gynecol Sci [Internet]. 2015;58:475-80. Crossref

8. Ueda Y, Kimura A, Kawahara E, Nakanishi I, Kitagawa H. Malignant melanoma arising in a dermoid cyst of the ovary. Cancer [Internet]. 1991;67:3141-5. Crossref

9. Boughton RS, Hughmanick S, Marin-Padilla M. Malignant melanoma arising in an ovarian cystic teratoma in pregnancy. $\mathrm{J}$ Am Acad Dermatol [Internet]. 1987;17:871-5. $\underline{\text { Crossref }}$ 